\title{
Comparative Evaluation of the Efficacy of Calcium Sulfate Bone Grafts in Crystalline and Nano-Crystalline Forms in Fresh Extraction Socket Sites: A Radiographic and Histological Pilot Study
}

\author{
Ashish Jain, Rashi Chaturvedi, Bindiya Pahuja
}

\begin{abstract}
Aim: Extraction site reconstruction is essential for alveolar ridge preservation, keeping in mind future placement of implants. In an attempt to preserve the alveolar bone and to avoid ridge augmentation prior to implant placement, numerous biocompatible regenerative materials have been used immediately following tooth extraction to fill the socket.
\end{abstract}

Methodology: This article is a pilot trial presenting early trends of the comparative use of two forms of calcium sulfate, i.e. medical grade (Dentogen) ${ }^{\circledR}$ and nano-crystalline (Nanogen) ${ }^{\circledR}$ as bone graft materials in immediate extraction sockets of three cases, based on histological and radiological assessments.

Results: At the end of 4 months following grafting, the extraction sites in all the three cases revealed no significant difference between the two materials. Radiographic assessment revealed an almost complete graft resorption and replacement with spongy bone with bone density comparable to the surrounding bone. Histopathological assessment revealed that $100 \%$ of the bone was vital with $52 \%$ trabecular bone and $48 \%$ bone marrow.

Conclusion: Calcium sulfate both medical grade and nanocrystalline form hold a valid premise for use as regenerative materials in extraction sockets with no significant differences seen between them in this pilot trial.

Keywords: Regeneration, Extraction socket, Bone graft, Calcium sulfate, Nano-Crystalline calcium sulfate.

How to cite this article: Jain A, Chaturvedi R, Pahuja B. Comparative Evaluation of the Efficacy of Calcium Sulfate Bone Grafts in Crystalline and Nano-Crystalline Forms in Fresh Extraction Socket Sites: A Radiographic and Histological Pilot Study. Int J Oral Implantol Clin Res 2012;3(1):58-61.

\section{Source of support: Nil}

Conflict of interest: None declared

\section{INTRODUCTION}

Regeneration of periodontium aims at restoring the original architecture and function of the tissues lost due to disease. ${ }^{1}$ Bone is, one of the few organs, able to self-regenerate following injury, however, when the damage is sufficiently severe, bone may not heal properly and regain its original mechanical function and, therefore, massive bone defects are a great challenge to reconstructive periodontal surgeries. Extraction site reconstruction is essential for preservation of alveolar ridge height and width, keeping in mind future placement of implants. ${ }^{2}$ Immediately following extraction, the socket is filled with blood coagulum and by 4 to 6 weeks, most of the alveolus are filled with woven bone, while the soft tissue becomes keratinized and, by the end of 4 to 6 months, the mineral tissue within the socket is reinforced with layers of lamellar bone. ${ }^{3,4}$ However, this process takes long time to reach the height and width of the adjoining sites. Studies have shown the beneficial effects of use of bone grafts in augmenting the alveolus following extractions as compared to the socket healing alone. ${ }^{5,6}$ Bone grafting has been used since times immemorial to replace this lost bone through the process of osteogenesis, osteoconduction or osteoinduction and it has been shown to promote regeneration and inhibit the epithelial migration by a process of contact inhibition. Autogenous bone grafts have always served as a gold standard for regeneration. However, problems, such as their procurement, quantity obtained, unpredictable resorption and need for a second surgical site, make their use difficult. ${ }^{7}$ Allografts, especially DFDBA and xenografts, such as Bio-oss, have been greatly used for various regenerative treatment purposes including augmentation of extraction sockets. Their use, however, is faced with problems regarding their immunogenicity, immunological reactivity and risk of disease transfer. All this led to the development of synthetically derived bone graft materials called alloplasts. ${ }^{8}$ Calcium sulfate and calcium phosphate compounds are attractive alternatives to autografts because of their biocompatibility, handling characteristics, porosity and different rates of dissolution, chemical and physical resemblance to bone mineral and potentially unlimited supply at a modest cost. Bone augmentation techniques using calcium sulfate (i.e. alloplasts) have demonstrated potential in surgical therapy for $>100$ years. It has been found to be biocompatible, biodegradable, osteoconductive, safe and nontoxic and also exhibits angiogenic, hemostatic and barrier membrane properties. Studies have shown excellent results with the use of this material in extraction socket defects. ${ }^{9-11}$ A nanocrystalline form of this material has been developed with a much smaller particle size and an advantage of being sustained release with a slower rate of resorption as 
compared to the original medical grade calcium sulfate. ${ }^{12}$ The present study aims at comparatively evaluating these two forms of calcium sulfate, i.e. medical grade (Dentogen) ${ }^{\circledR}$ and nano-crystalline (Nanogen) ${ }^{\circledR}$ forms in extraction sockets based on histological and radiological assessments.

\section{MATERIALS AND METHODS}

This case series presents an early trend of the study as a pilot trial on three cases; two of which were treated using nano-crystalline calcium sulfate hemihydrate bone graft (Nanogen) ${ }^{\circledR}$ and one case was treated using medical grade calcium sulfate hemihydrate bone graft (Dentogen) ${ }^{\circledR}$. The study included willing subjects slated for extractions due to presence of any ongoing pathosis and subsequent implant placement. They were systemically healthy with no history of any ongoing pregnancy, smoking or traumatic extractions. All the patients enrolled for the study were administered phase I periodontal therapy, following which they were equally divided into two groups: A and B by computer generated random numbers. An informed consent was obtained from each of the patients after thoroughly explaining the treatment protocol. Extractions were carried out under local anesthesia (2\% lidocaine and 1:100000 adrenaline) after elevating the buccal and lingual mucoperiosteal flaps with minimal trauma preferably using a periotome so as to preserve the walls of the socket for graft placement. Thus, each of the sockets taken up for treatment had a four-walled configuration. The extraction sockets were thoroughly debrided and then decorticated with a no. 1/2 round bur and copious irrigation to enhance vascular supply. In group A patients, the sockets were filled with nano-crystalline calcium sulfate hemihydrate bone grafts (Nanogen $)^{\circledR}$ immediately after local control of bleeding at the extraction sites and, in group B patients, the sockets were filled with medical grade calcium sulfate hemihydrate bone grafts (Dentogen) ${ }^{\circledR}$. Following adequate condensation of the graft in the socket, the flaps were repositioned and sutured using 3-0 black silk sutures. Postoperative care comprised of $0.12 \%$ chlorhexidine rinses twice daily for 4 weeks, systemic antibiotics (amoxicillin 500 mg every 8 hours) for 1 week, analgesic medication (ibuprofen 400 mg every 8 hours) for 3 days and the same regimen was extended as per the need of the subject. Sutures were removed after 10 to 14 days. The sites were allowed to heal and any adverse event or complication observed was noted during the course of the study.

Radiographic evaluation: Radiographs were taken at baseline, i.e immediately after graft placement, at 1, 3 and at 4 months after the surgical procedure to evaluate the change in the radiographic density of bone. The radiographs were taken by a paralleling technique with the following parameters; tube current of $8 \mathrm{~mA}$, tube voltage of $70 \mathrm{kV}$ and the length of the cone (PIG) as 12 inches.

Histopathological evaluation: Trephined cylindrical sample cores of newly formed intrasocket tissue, $2 \mathrm{~mm}$ in diameter, $7 \mathrm{~mm}$ in length, were obtained after 4 months of the surgical procedure. The samples were preserved in $10 \%$ formalin and then sent for histopathological evaluation in a specialized laboratory. Results were compared in terms of the extent of resorption of both Nanogen ${ }^{\circledR}$ and Dentogen ${ }^{\circledR}$ and the histological assessment of the quality of bone formed.

\section{RESULTS}

Results showed that at the end of 4 months following grafting the extraction sites in all the three cases healed with no adverse event and clinical evaluation revealed a fully keratinized soft tissue covering the underlying bone. Transgingival probing of the grafted area revealed the presence of solid underlying bone. Radiographic assessment showed the presence of some remnants of the bone graft materials in all the three cases but most of the bone graft

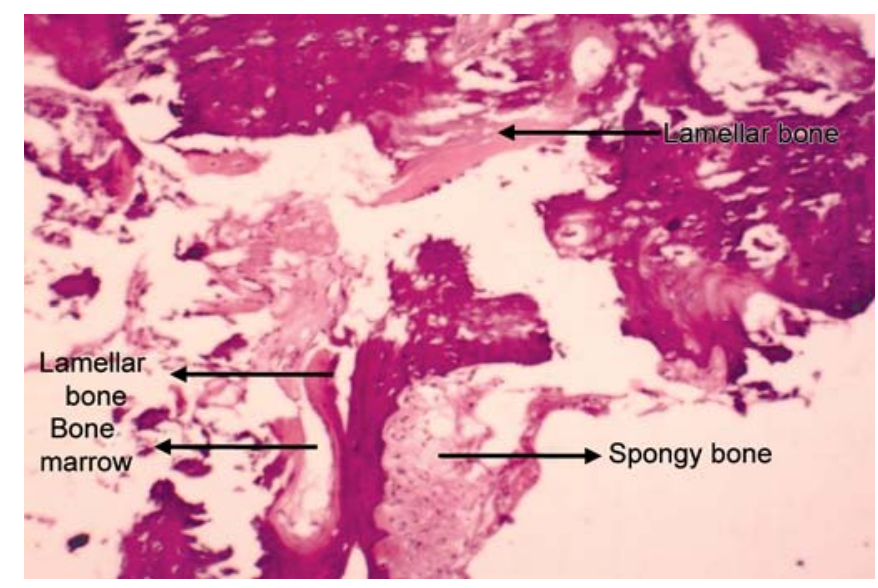

Fig. 1: Nano-crystalline calcium sulfate hemihydrate

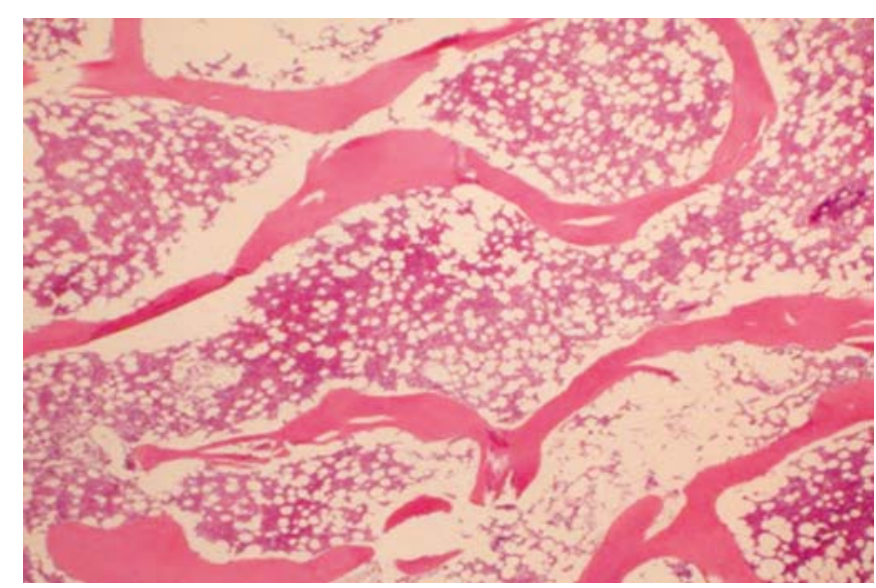

Fig. 2: Calcium sulfate hemihydrate (medical grade) 
had resorbed to be replaced with spongy bone with bone density comparable to the surrounding bone. Histopathological assessment revealed that $100 \%$ of the bone was vital with evidence of osteoclasts, osteoblasts and numerous blood vessels. On a quantitative estimation approximately $52 \%$ of the tissue was bone and $48 \%$ was bone marrow (Figs 1 and 2).

\section{DISCUSSION}

Alveolar ridge augmentation is often deemed necessary prior to replacement of missing teeth with implants. Loss of bone may occur due to presence of an endodontic pathology, periodontitis, trauma or aggressive maneuvers during extraction. Hence, it becomes prudent to preserve the alveolar ridge during extraction procedures. The degree of ridge resorption greatly increases with the time elapsed since tooth extraction with the greatest occurring in the immediate postextraction period. ${ }^{13,14}$ Schropp et al suggested, after a 12-month prospective study that severe changes in the bone contour occurred following extraction to the order of $50 \%$ decrease in bone width with 2/3rd occurring in the first 3 months. ${ }^{15}$ In an attempt to preserve the alveolar bone and to avoid ridge augmentation prior to implant placement, numerous biocompatible regenerative materials have been used immediately following tooth extraction to fill the socket. ${ }^{16-18}$ Medical grade calcium sulfate hemihydrate is a fascinating material with unique physical and chemical properties. Upon implantation in the body, it dissolves into calcium and sulfate ions and the calcium ions combine with phosphate ions from body fluids to form calcium phosphate. This forms an osteoconductive lattice of biologic apatite that stimulates bone growth into the defect. Infrared spectroscopy studies have shown that the newly deposited material is mainly carbonated hydroxyapatite which is similar to the apatite naturally present in bone. As calcium sulfate undergoes degradation in the osseous defect, a local decrease in $\mathrm{pH}$ occurs which results in demineralization of the defect walls producing a release of growth factors, such as bone morphogenetic protein-2 (BMP-2), BMP-7, TGF- $\beta$ and PDGF-BB that enhance bone regeneration., ${ }^{9,10}$ Numerous studies have cited the advantages of the use of calcium sulfate bone grafts in various osseous defects and shown them to exhibit superior results over other alloplasts and comparable results to those of autografts. ${ }^{19,20}$ No osteoprotective regenerative barrier was used as both the forms of calcium sulfate bone grafts under study had a self- retentive property. This material, however, was observed to resorb too quickly before bone could regenerate and pronounced shrinkage of the graft material during resorption process caused a decrease in the volume of regenerated bone compared to the volume of the graft. To overcome this drawback, a nano-composite graft was developed in which microcrystalline calcium sulfate was converted to grains of calcium sulfate (size range 200 to 900 nanometers), which are tightly compressed together to form granules in sizes ranging from 400 to 1000 microns. This unique microscopic structure enabled it to undergo controlled degradation over a period of 12 weeks as compared to 4 to 6 weeks for traditional calcium sulfate. The present study aims to comparatively assess these two forms of calcium sulfate. The results of this pilot trial on three cases were found to be comparable with no specific difference found with the use of these two forms of calcium sulfate graft material. The success of osseointegrated implants rests in the quality and quantity of residual bone at the recipient site at the time of implant placement. ${ }^{2}$ The use of both of these materials in freshly extracted sockets resulted in the formation of good quality bone with sufficient strength to be considered favorably for implant placement.

\section{REFERENCES}

1. Caton JG, Greenstein G. Factors related to periodontal regeneration. Periodontol 2000 1993;1:9-15.

2. Irinakis T. Rationale for socket preservation after extraction of a single-rooted tooth when planning for future implant placement. J Can Dent Assoc 2006;72(10):917-22.

3. Jahangiri L, Devlin H, Ting K, Nishimura I. Current perspectives in residual ridge remodeling and its clinical implications: A review. J Prosthet Dent 1998;80(2):224-37.

4. Cardaropoli G, Araujo M, Lindhe J. Dynamics of bone tissue formation in tooth extraction sites. An experimental study in dogs. J Clin Periodontol 2003;30(9):809-18.

5. Iasella JM, Greenwell H, Miller RL, Hill M, Drisko C, Bohra AA, et al. Ridge preservation with freeze-dried bone allograft and a collagen membrane compared to extraction alone for implant site development: A clinical and histologic study in humans. J Periodontol 2003;74(7):990-99.

6. Barone A, Aldini NN, Fini M, Giardino R, Guirado JLC, Covani U. Xenograft versus extraction alone for ridge preservation after tooth removal: A clinical and histomorphometric study. J Periodontol 2008;79:1370-77.

7. Reidy A, Mary E. Bone replacement grafts: The bone substitutes. Dent Clin North Am 1998;42(3):491-504.

8. Yukna RA. Synthetic bone grafts in periodontics, Periodontologv 2000;1993;1:92-99.

9. Kutkut A, Andreana S, Kim HL, Monaco E. Extraction socket preservation graft prior to implant placement with calcium sulfate hemihydrate and platelet-rich plasma: A clinical and histomorphometry study in human subjects. J Periodontol 2011 Aug 23. [Epub ahead of print]

10. Ruga E, Gallesio C, Chiusa L, Boffano P. Clinical and histologic outcomes of calcium sulfate in the treatment of postextraction sockets. J Craniofac Surg 2011;22(2):494-98.

11. Guarnieri R, Pecora G, Fini M, Aldini NN, Giardino R, Orsini G, Piattelli A. Medical grade calcium sulfate hemihydrate in healing of human extraction sockets: Clinical and histological observations at 3 months. J Periodontol 2004;75(6):902-08. 
12. Park YB, Mohan K, Al-Sanousi A, Almaghrabi B, Genco RJ, Swihart MT, Dziak R. Synthesis and characterization of nanocrystalline calcium sulfate for use in osseous regeneration. Biomed Mater Aug 26 2011;6(5):055007 [Epub ahead of print].

13. Pietrokovski J, Massler M. Alveolar ridge resorption following tooth extraction. J Prosthet Dent 1967;17(1):21-27.

14. Lam RV. Contour changes of the alveolar processes following extractions. J Prosthet Dent 1960;10:25-32.

15. Schropp L, Wenzel A, Kostopoulos L, Karring T. Bone healing and soft tissue contour changes following single-tooth extraction: A clinical and radiographic 12-month prospective study. Int $\mathrm{J}$ Periodontics Restorative Dent 2003;23(4):313-23.

16. Artzi Z, Tal H, Dayan D. Porous bovine bone mineral in healing of human extraction sockets (Part 1): Histomorphometric evaluations at 9 months. J Periodontol 2000;71(6):1015-23.

17. Gross JS. Bone grafting materials for dental applications. A practical guide. Compend Contin Educ Dent 1997;18:1013-24.

18. Lekovic V, Camargo PM, Klokkevold PR, et al. Preservation of alveolar bone in extraction sockets using bio-absorbable membranes. J Periodontol 1998;69:1044-49.

19. Melo LG, Nagata MJ, Bosco AF, Ribeiro LL, Leite CM. Bone healing in surgically created defects treated with either bioactive glass particles, a calcium sulfate barrier, or a combination of both materials. A histological and histometric study in rat tibias. Clin Oral Implants Res 2005;16(6):683-91.

20. Orsini M, Orsini G, Benlloch D, Aranda JJ, Lazaro P, Sanz M, De Luca M, Piattelli A. Comparison of calcium sulfate and autogenous bone graft to bioabsorbable membranes plus autogenous bone graft in the treatment of intrabony periodontal defects: A split-mouth study. J Periodontol 2001;72(3):296-302.

\section{ABOUT THE AUTHORS}

\section{Ashish Jain (Corresponding Author)}

Professor, Department of Periodontology, Dr HSJ Institute of Dental Sciences, Chandigarh, India, e-mail: ashish@justice.com

\section{Rashi Chaturvedi}

Reader, Department of Periodontology, Dr HSJ Institute of Dental Sciences, Chandigarh, India

\section{Bindiya Pahuja}

Postgraduate Student, Department of Periodontology, Government Dental College, Shimla, Himachal Pradesh, India 